\title{
CORRESPONDENCE
}

\section{OCULAR TORTICOLLIS}

\section{To the Editors of The British Journal of Ophthalmology.}

SIR,-Mr. Temple-Smith, in a letter appearing in your September issue, criticises some of the statements in the brief abstract published in the Brit. Jl. of Ophthal. of a paper on ocular torticollis read by me at the last meeting of The Ophthalmological Society.

It is impossible adequately to discuss in a short letter many of the points he has raised, and most of them were dealt with at some length in my paper, which will be published in full in the forthcoming volume of the Transactions. To this I must refer Mr. Temple-Smith for further elucidation of my views on the subject.

\section{Yours truly,}

W. H. MCMULLEN.

LONDON,

September 27, 1934.

\section{OBITUARY}

\section{W. C. POSEY}

We much regret to learn that Dr. Posey died suddenly at Naples on September 5, just as he had embarked on his homeward journey to the States.

William Campbell Posey was born in Philadelphia in 1868, the son of Dr. David Posey. Educated at the Episcopal Academy, he proceeded to the University of Pennsylvania and qualified in 1889. After the customary period as House Surgeon, he spent a couple of years in post-graduate study in Berlin, Göttingen, Paris and London, where he worked at Moorfields. Posey was connected with numerous hospitals, the chief of which was the Wills Hospital, where he was Assistant Surgeon from 1893 to 1902, and afterwards Surgeon. With Dr. S. H. Brown he was the author of the History of Wills Hospital and traced the growth 
of ophthalmology in Philadelphia and in the States during the past 100 years. This work was reviewed in our columns in Vol. XVI, p. 115, by his intimate friend, Mr. Treacher Collins.

Posey and Spiller's "The Eye and the Nervous System " was published in 1906 and was at once recognized as a pioneer work in this subject, while his "Hygiene of the Eye," published in 1918 , is a classic.

Posey was President of the American Ophthalmological Society in 1929; he was also a very active member of the National Society for the Prevention of Blindness, and became a member of its Board of Directors in 1922. Probably the last thing he wrote was the article published in the Sight-Saving Review this summer. The title is "The romance in the movement for the Prevention of Blindness," and in it he traces the history of the movement from the days when Benjamin Gibson of Manchester emphasized the connection, hinted at by Quellmaltz about half a century earlier, between 'babies' sore eyes' and vaginal discharge in the mother. Gibson's work was not recognized at the time, and so late as 1837 we find the Spanish Cortes decreeing that babies be baptized " with warm water, since the cold water commonly employed was so often followed by sore eyes and in many cases by blindness."

The work of Credé and of Ernst Fuchs, Lucien Howe, Park Lewis and the Misses Edith and Winifred Holt with that of Louisa Lee Schulyer is noticed.

We are indebted to Mr. Lewis Carris for sending us a clipping from the New York Times of September 6, and a reprint of Posey's last article.

Much sympathy will be felt for Dr. Posey's widow and children; his untimely death is a heavy blow to ophthalmology.

\section{ARTHUR ZORAB}

WE much regret to record the death of Mr. Zorab of Southampton, which occurred at the end of August, 1934. Mr. Zorab was born in 1880 , the son of Col. Zorab, I.M.S.; he was educated at Guy's Hospital and took the conjoint diploma in 1906, graduating M.B., B.S. at the University of London in the same year. Settling at Southampton he rapidly made his mark as an ophthalmic surgeon. $\mathrm{He}$ was Hon. Surgeon to the Southampton Eye Hospital and Ophthalmic Surgeon to the Royal Hants. County Hospital at Winchester. Mr. Zorab was a member of the Ophthalmolgical Society of the United Kingdom and Oxford Congress, and had been chief assistant in the Ophthalmic Department at Guy's 